\title{
Delayed neurological deterioration following atlantoaxial facet joint distraction and fixation in a patient with Chiari malformation type I
}

\author{
Tatsushi Inoue, MD, PhD, Natsuki Hattori, MD, PhD, Tsukasa Ganaha, MD, PhD, \\ Tadashi Kumai, MD, Shinichiro Tateyama, MD, and Yuichi Hirose, MD, PhD \\ Department of Neurosurgery, Fujita Health University, Aichi, Japan
}

Chiari malformation type I (CM-I) is typically treated with foramen magnum decompression. However, a recent study proposed a new technique for patients with CM-I, wherein only short atlantoaxial joint fusion and distraction is applied. Posterior fusion with or without atlantoaxial distraction is a potential option for patients with CM-I associated with basilar invagination or complex anomalous bony craniovertebral junction pathology, since this procedure allows clinicians to avoid using the technically demanding transoral approach in which some or all of the odontoid tip is invisible. Distraction of the atlantoaxial joint reduces ventral cervicomedullary compression, leading to neurological improvement. Here, the authors report the case of a 50-year-old woman with CM-I plus basilar invagination whose condition immediately improved but then gradually deteriorated following atlantoaxial joint distraction and fusion. Therefore, the authors performed endonasal/transoral odontoidectomy, which resulted in prolonged neurological recovery. Short atlantoaxial fusion with distraction is a smart and ideal surgical planning concept that can result in significant neurological improvement. However, this case suggests that anterior odontoidectomy is still an essential element of the intervention strategy for patients with CM-I with complex craniovertebral junction pathology.

https://thejns.org/doi/abs/10.3171/2017.7.SPINE161383

KEY WORDS Chiari malformation type I; basilar invagination; atlantoaxial fixation; endonasal surgery; endoscope; cervical

$\mathrm{S}$ ELECTING the appropriate surgical approach and management strategy for the treatment of craniovertebral junction abnormalities remains a challenge. Goel developed a unique and elegant technique for treating Chiari malformation type I (CM-I), ${ }^{4,7}$ which is often associated with such abnormalities. This technique has the potential to replace the conventional approach of foramen magnum decompression. In Goel's technique, the atlantoaxial joint is distracted using a metal spacer with C-1 lateral mass and C-2 pars screws. In this technique, the odontoid tip is shifted caudally, and the space available for neural structures increases. With this technique, there is supposedly no need for conventional transoral odontoidectomy or tonsillectomy. However, the C1-2 motion unit is inevitably sacrificed, and lethal complications, including vertebral artery injury, are possible. Therefore, despite its utility, this technique has aroused considerable controversy. ${ }^{2,5}$
Here, we describe a patient with CM-I with basilar invagination in whom delayed neurological deterioration was observed after the use of Goel's atlantoaxial distraction and fixation approach. Additionally, we discuss the potential mechanisms underlying this deterioration and suggest alternative valid surgical strategies.

\section{Case Report}

A 50-year-old woman initially presented to an affiliated hospital with dizziness, nystagmus, and cerebellar ataxia. $\mathrm{CT}$ and MRI revealed CM-I with basilar invagination (Fig. 1). The patient's lumbar spine MRI study showed normal findings without cord tethering. The patient provided informed consent, allowing her relevant medical information to be published.

The patient had previously undergone a simple foramen magnum decompression at an affiliated hospital. Post- 

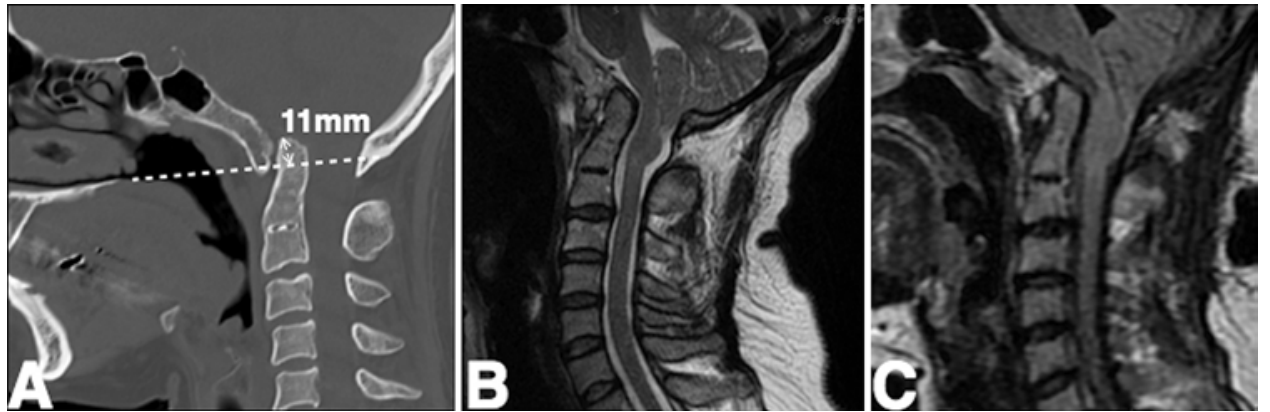

FIG. 1. A: Preoperative sagittal reconstructed CT scan. The tip of the odontoid process is invaginated into the foramen magnum $11 \mathrm{~mm}$ above the McGregor line (drawn to the most caudal point of the occiput, which is identified as the border between the assimilated C-1 and occiput). B and C: Sagittal MR images obtained before (B) and after (C) foramen magnum decompression. Compression around the cervicomedullary junction remains unchanged.

operatively, the patient's neurological symptoms gradually progressed. Cerebellar and trunk ataxia also became prominent. Four years later, the patient was referred to our institution for central respiratory dysfunction at night. Imaging revealed persistent brainstem compression despite the previous foramen magnum decompression (Fig. 1C). We therefore performed indirect decompression by atlantoaxial facet joint release/distraction with intraarticular spacer placement and fixation (Fig. 2). We used cross-laminar screws rather than $\mathrm{C}-2$ pars screws because a preoperative $3 \mathrm{D}$ simulation using the neuronavigator workstation indicated that the pars screws were too large for the narrow pars interarticularis. After the procedure, the ventral brainstem compression was partially relieved (Fig. 3B), and the patient's neurological symptoms markedly improved. The patient was able to walk stably, and her intermittent respiratory arrest at night had disappeared. Four months after the second operation, however, her walking deteriorated. Six months after the second operation, she required a wheelchair due to trunk and limb ataxia. Hoarseness and swallowing disturbances were also prominent. Follow-up MRI revealed slight narrowing of the CSF space around the cerebellar tonsil (Fig. 3C). Radiographs and CT images did not indicate instrument failure, although slight cage subsidence was present (Fig. 4). Based on these findings, we considered that the cage subsidence might have enhanced ventral brainstem compression, resulting in neurological deterioration.

We adopted an endoscopic combined endonasal and transoral approach for the final operation to treat the basilar invagination at our university because it is difficult to reach the odontoid tip using the microscopic transoral approach, as it is situated $11 \mathrm{~mm}$ above the McGregor line (Fig. 1A) for basilar invagination. During the operation, we were able to completely remove the odontoid process and sufficient brainstem decompression was achieved (Fig. 5). Postoperatively, the patient's trunk and limb ataxia were successfully resolved, and her hoarseness and swallowing disturbances had disappeared. Three months after the endoscopic odontoidectomy, the patient was able
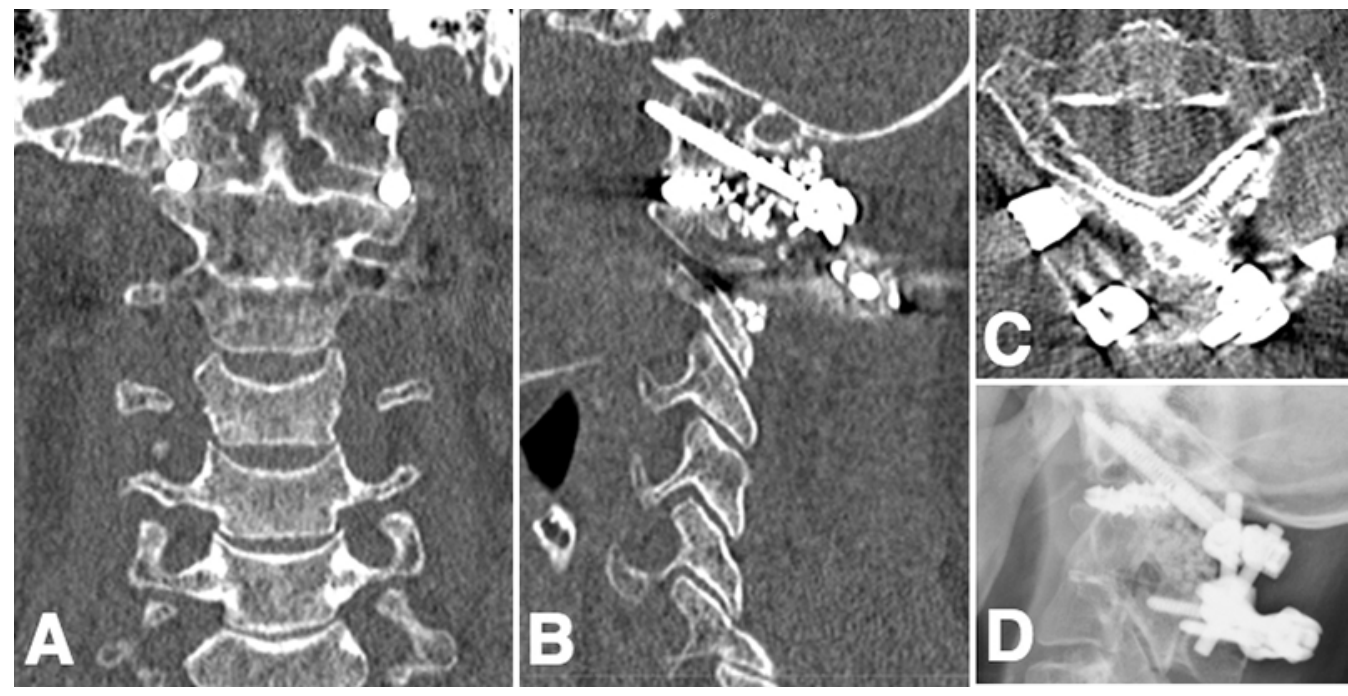

FIG. 2. A and B: Postoperative coronal (A) and sagittal (B) reconstructed CT scans showing the distracted atlantoaxial joint and autologous and artificial bone chips in and around the facet joint. C: Axial scan showing well-placed C-2 laminar screws. D: Plain lateral (right side) cervical spine radiograph showing the contour of the instrumented construct. C-2 and C-3 are assimilated. 


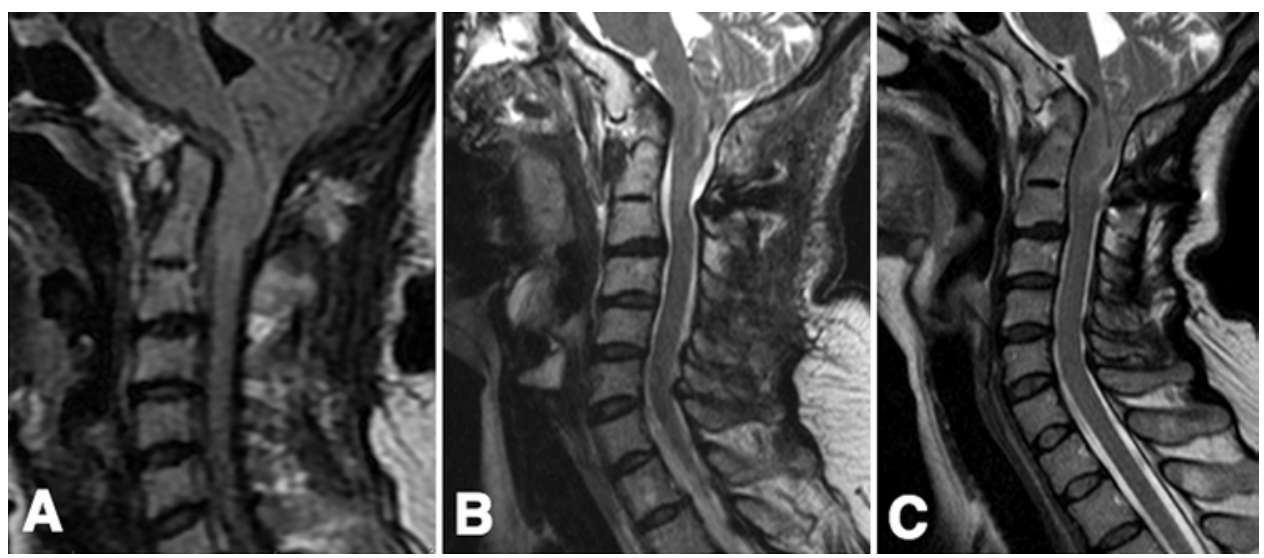

FIG. 3. A and B: Sagittal MR images acquired after foramen magnum decompression (A) and atlantoaxial distraction (B) showing partial relief of the ventral cervicomedullary junction compression. C: Follow-up MR image acquired 1 year $(\mathrm{C})$ after atlantoaxial distraction. The CSF spaces around the cerebellar tonsil are slightly narrowed.

to walk while at home without assistance and was living life independently. Ten months after the endoscopic odontoidectomy, at the last follow-up examination, the patient was able to walk both at home and outside on her own. At the latest follow-up examination, which was carried out 14 months after the operation, the patient was able to take care of her family, prepare a meal, and clean her home. CT images indicated a diminished halo and formation of a lateral bridging spur around the spacers, indicating that bone fusion was ongoing (Fig. 4C).

\section{Discussion}

CM-I associated with craniovertebral junction bone anomalies, especially basilar invagination, is still difficult to treat and manage. Simple decompression procedures, such as foramen magnum decompression, might be insufficient for the treatment of patients with basilar invagination. Anterior transoral odontoid resection ${ }^{3,15}$ is effective but is often difficult to perform because the soft palate hinders visualization of the odontoid process. Recently,
Goel reported a new technique that avoids using the transoral approach. ${ }^{4,7}$ This technique is called atlantoaxial joint distraction and fixation, which is based on the author's beliefs on the pathogenesis of CM-I and his clinical experience. Specifically, Goel has documented atlantoaxial instability in CM-I and speculated that CM-I might be an innate protective mechanism that helps to reduce the effects of instability and cord compression produced by the odontoid process, similar to an "air bag."

We adopted Goel's atlantoaxial facet joint distraction and fixation technique as a salvage surgery in a patient in whom simple foramen magnum decompression was previously performed despite the presence of basilar invagination. Remarkable neurological improvement was observed after a posterior atlantoaxial distraction and fixation method, but our patient's symptoms eventually returned.

Several potential mechanisms may underlie the delayed neurological deterioration that we observed in this patient.

The first possible mechanism is cage subsidence, as cages were used as spacers in the atlantoaxial joint. Dis-

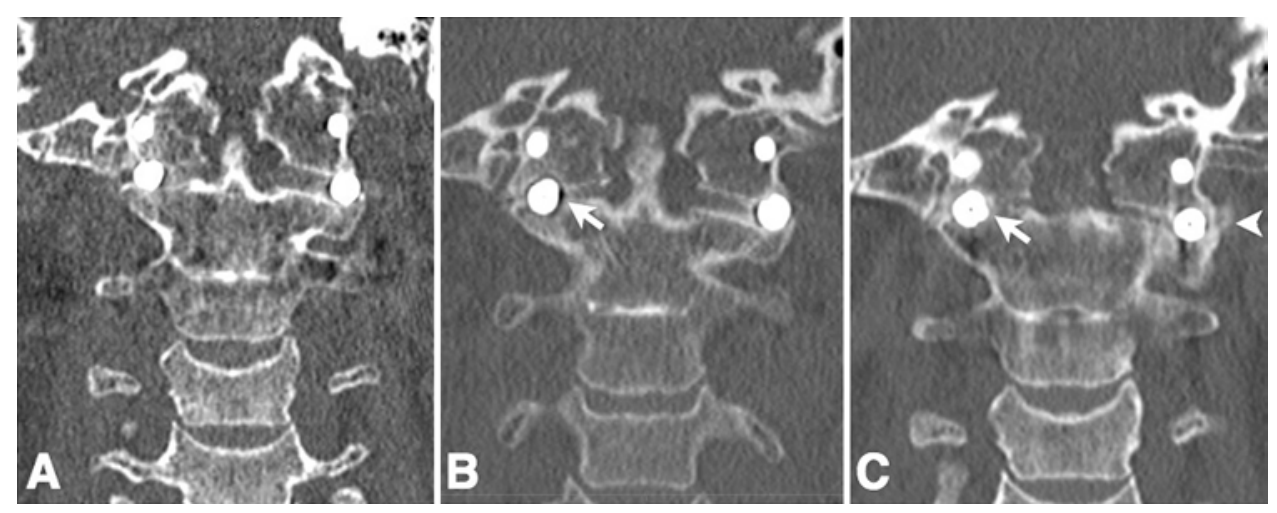

FIG. 4. A and B: Follow-up coronal reconstructed CT scans obtained at 1 month (A) and 1 year (B) after atlantoaxial distraction, showing slight spacer subsidence between the atlantoaxial joint with slight haloing around the right spacer (arrow). C: Fourteen months after the endoscopic odontoidectomy, the halo had diminished (arrow) and a lateral bone spur had formed (arrowhead). This indicated that solid fusion was ongoing at this time. 


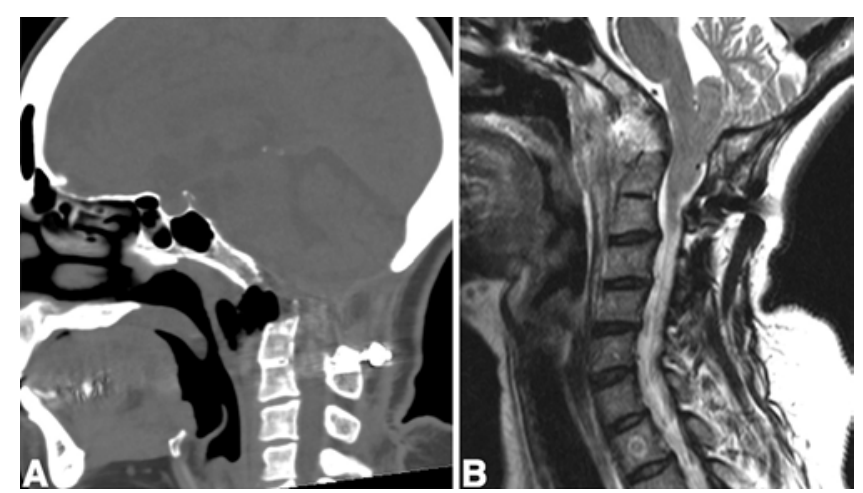

FIG. 5. Sagittal reconstructed CT image (A) and MR image (B) obtained after endoscopic odontoidectomy. Ventral compression of the cervicomedullary junction was eliminated.

traction of the atlantoaxial joint shifts the odontoid tip caudally and reduces the brainstem compression caused by the odontoid process. However, subsidence of the spacers before bone fusion could result in reversion of the pathology and delayed neurological deterioration.

A second possible mechanism is micromotion, as indicated by the slight haloing around the interfacet spacers (Fig. 4). We know that this process can lead to bone fusion, as we reported in a case series of patients with subaxial cervical fusion using a stand-alone cage, ${ }^{9}$ especially in the presence of surrounding bone formations. For example, bridging bones can stably form in a short period of time.

Third, spinal cord distraction or stretching can lead to worsening of neurological symptoms. However, the immediate neurological improvement following $\mathrm{Cl}-2$ distraction and recovery after an additional endoscopic decompression suggests that distraction injury was not the cause of delayed deterioration in this case.

The fourth potential mechanism is insufficient decompression of the brainstem. According to Goel's method, the brainstem is decompressed indirectly by the caudal transposition of the odontoid tip while the odontoid process is kept intact. However, the brainstem may remain partly compressed, resulting in prolonged disturbed microcirculation and/or neuronal degeneration that is undetectable by MRI.

A fifth possible mechanism is the movement of the craniocervical junction rostrally relative to the hard palate. Indeed, Mallory et al. reported that the craniocervical junction undergoes dynamic position changes during a person's lifetime. ${ }^{13}$ The position of the craniocervical junction, measured as the distance between the McGregor line and the inferior C-2 endplate, increases through the 4th and 5th decades of life and is followed by settling. Unfortunately, measuring the position of the craniocervical junction based on the McGregor line was impossible in our case because the caudal part of the occiput, which is used as a reference for locating the line, was lost during foramen magnum decompression. Collectively, the aforementioned mechanisms likely explain why atlantoaxial distraction and fusion was unable to sufficiently provide prolonged neurological recovery.

The validity of atlantoaxial distraction and fusion for
CM-I remains unclear. Goel proposed his atlantoaxial joint distraction and fixation technique as a replacement for foramen magnum decompression in patients with CMI; moreover, he insisted that there is no need for transoral odontoidectomy or tonsillectomy, which were occasionally performed with foramen magnum decompression in certain CM-I patients. ${ }^{4}$ These claims have generated considerable discussion in the field. ${ }^{2,5,6,10}$ The Pediatric Craniocervical Society even published a report against Goel's novel technique of atlantoaxial fixation for $\mathrm{CM}-\mathrm{I},{ }^{2}$ since many patients with CM-I without basilar invagination seem to recover well after foramen magnum decompression; thus, there is no need to subject them to the potentially lethal vertebral artery injuries associated with atlantoaxial fixation and screw placement. We adopted Goel's atlantoaxial distraction/fixation technique in the present case because foramen magnum decompression was not successful, and another report stated that his technique provides relief. ${ }^{19}$ Notably, we also included the occipital bone for fixation, although Goel criticized this as unnecessary and unfavorable to implant strength. We respect Goel's opinion and his unique and original surgical intervention for CM-I, but since only transient neurological relief was achieved, his technique likely rescued our patient and initially allowed us to avoid performing the technically demanding odontoidectomy.

In conclusion, Goel's technique is favorable for CM-I with basilar invagination and can be applied alone or combined with anterior odontoidectomy (Fig. 6). In CMI, vertical instability as described by Goel ${ }^{4}$ is difficult to verify preoperatively using imaging. We agree with him based on our experience, although measuring instability in an objective manner is difficult. Therefore, C1-2 spacers should be used for the treatment of CM-I with basilar invagination if the space is reserved intraoperatively. This space can become difficult to access in the presence of secondary bridging bone formations between $\mathrm{C}-1$ and $\mathrm{C}-2$ or in the fixed condition. In these cases, simple C1-2 fixation without a spacer is performed. The lesson learned from this case is that simple foramen magnum decompression is insufficient for the treatment of CM-I with basilar invagination. We should perform $\mathrm{C} 1-2$ distraction in addition to foramen magnum decompression for patients with complex pathologies such as that evidenced here. This treatment should be followed by anterior decompression via odontoidectomy if symptoms persist. C1-2 distraction may be altered by simple $\mathrm{C} 1-2$ fixation if a 1-step anterior odontoidectomy with C1-2 fixation is planned or if motor evoked potentials indicate worsening neurological symptoms during the distraction procedure (Fig. 6). Although craniocervical fixation is an option for the treatment of this pathology, we must recognize that swallowing disturbances are possible adverse effects of craniocervical fixation in certain settings. ${ }^{14}$ Maximal motion preservation with the greatest degree of decompression should be pursued. The spacer should be removed if motor evoked potential monitoring indicates deterioration during surgery, if it is dislodged into the spinal canal, or if it results in pseudarthrosis with considerable postoperative screw loosening.

It is well known that distraction or stretching of the spi- 


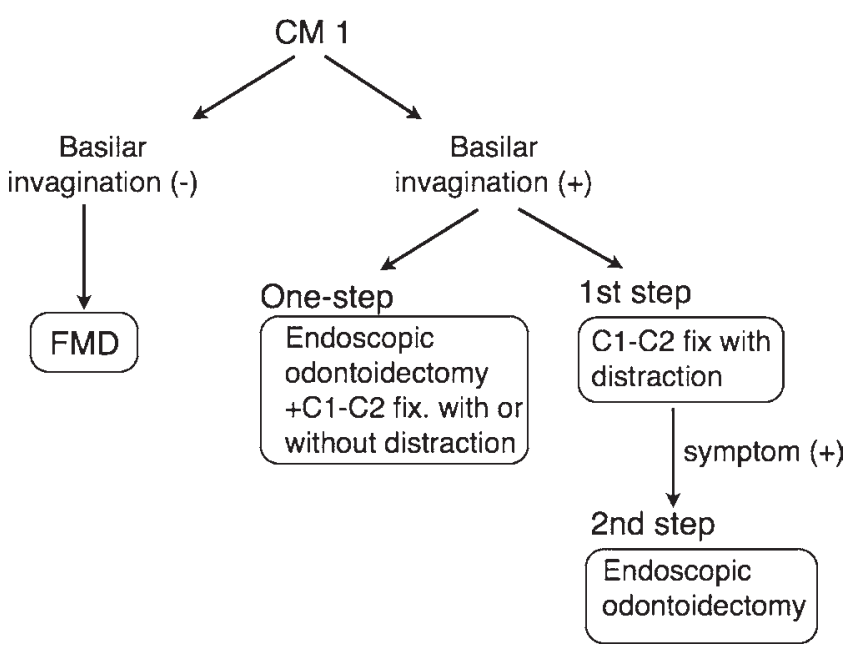

FIG. 6. Flow diagram illustrating our suggested surgical decision-making process for the treatment of patients with CM-I. Fix = fixation; FMD = foramen magnum decompression.

nal cord can lead to worsening of neurological symptoms. In an experimental porcine study, Hong et al..$^{8}$ demonstrated that continuous spinal distraction of $20 \mathrm{~mm}$ for $10 \mathrm{~min}$ utes induces spinal cord injury. Qiu et al. ${ }^{17}$ reported that the safe limit of distraction was $11.8 \pm 3.65 \mathrm{~mm}$ in a goat model. Kim et al. summarized other studies as well as their own based on human clinical operations in a report. ${ }^{12}$ The distraction lengths described by Abumi et al., ${ }^{1}$ Goel, ${ }^{7}$ Jian et al., ${ }^{11}$ Peng et al., ${ }^{16}$ and Kim et al. ${ }^{12}$ were $4.3 \pm 3.0$ $\mathrm{mm}$ (range $0-10 \mathrm{~mm}$ ), $6.2 \pm 3.1 \mathrm{~mm}$ (range $0-8 \mathrm{~mm}$ ), 3.7 \pm 2.0 (range $2-11 \mathrm{~mm}$ ), $9.3 \mathrm{~mm}$ (range not available), and $4.5 \pm 2.5 \mathrm{~mm}$ (range 1.0-9.4 mm), respectively. Regardless of the distraction length, electrophysiological monitoring is mandatory during the operation. Distractions of up to 10 $\mathrm{mm}$ seem to be safe under monitoring.

Despite the utility of the described technique, a safer atlantoaxial fusion with distraction approach is necessary. Recently Wei et al. ${ }^{18}$ used instrumented transoral atlantoaxial joint distraction and fixation for the treatment of basilar invagination with Klippel-Feil syndrome. While 1-step anterior indirect decompression and fixation is advantageous, the soft palate must be cut to obtain an operative field for the instrumented transoral approach. Thus, wound infection is possible and occurred in $10 \%$ of cases ( 1 of 10 cases).

Odontoidectomy performed via the endonasal and/or transoral route can be an important surgical option, especially in patients with CM-I with basilar invagination. In our patient, we resorted to odontoidectomy using an endoscopic combined endonasal and transoral approach because the odontoid tip was considerably above the McGregor line. The sufficient brainstem decompression that we achieved produced marked neurological improvements in the patient, as measured via outpatient follow-up examinations performed over the course of 1 year. Collectively, the findings from the present case suggest that new endoscopic techniques for the treatment of anterior craniovertebral junction abnormalities may be better and less invasive surgical options when neurological improvement is not gained or is limited following foramen magnum decompression with posterior fixation (Fig. 6).

Goel's influential technique of treating symptomatic Chiari malformation with posterior atlantoaxial distraction with intrafacet spacers avoids the transoral approach, which is difficult to perform in cases accompanied by basilar invagination. Our case suggests that persistent compression of the cervicomedullary junction following atlantoaxial joint distraction and fixation may lead to symptom recurrence. In the present era of endoscopic spine and skull base surgery, endoscopic endonasal/transoral odontoid resection is a less invasive rescue option for the treatment of complex CM-I with craniovertebral junction anomalies.

\section{References}

1. Abumi K, Takada T, Shono Y, Kaneda K, Fujiya M: Posterior occipitocervical reconstruction using cervical pedicle screws and plate-rod systems. Spine (Phila Pa 1976) 24:1425-1434, 1999

2. Brockmeyer DL, Oakes WJ, Rozzelle C, Johnston J, Rocque BG, Anderson RC, et al: Chiari malformation Type 1 and atlantoaxial instability: a letter from the Pediatric Craniocervical Society. J Neurosurg Spine 23:820-821, 2015

3. Crockard HA: Transoral surgery: some lessons learned. Br J Neurosurg 9:283-293, 1995

4. Goel A: Is atlantoaxial instability the cause of Chiari malformation? Outcome analysis of 65 patients treated by atlantoaxial fixation. J Neurosurg Spine 22:116-127, 2015

5. Goel A: Response. J Neurosurg Spine 23:821-823, 2015

6. Goel A: Response. J Neurosurg Spine 22:114-115, 2015

7. Goel A: Treatment of basilar invagination by atlantoaxial joint distraction and direct lateral mass fixation. J Neurosurg Spine 1:281-286, 2004

8. Hong JY, Suh SW, Lee SH, Park JH, Park SY, Rhyu IJ, et al: Continuous distraction-induced delayed spinal cord injury on motor-evoked potentials and histological changes of spinal cord in a porcine model. Spinal Cord 54:649-655, 2016

9. Inoue T, Mizuno J, Shouda M, Sano H, Nakagawa H: Refined anterior cervical discectomy and fusion using cylindrical cage, presented at the 24th Annual Meeting of the AANS/ CNS Section on Disorders of the Spine and Peripheral Nerves, Orlando, Florida, 2008 (Poster \#379)

10. Jea A: Chiari malformation I surgically treated with atlantoaxial fixation. J Neurosurg Spine 22:113-114, 2015

11. Jian FZ, Chen Z, Wrede KH, Samii M, Ling F: Direct posterior reduction and fixation for the treatment of basilar invagination with atlantoaxial dislocation. Neurosurgery 66: $678-687,2010$

12. Kim CH, Hong JT, Chung CK, Kim JY, Kim SM, Lee KW: Intraoperative electrophysiological monitoring during posterior craniocervical distraction and realignment for congenital craniocervical anomaly. Eur Spine J 24:671-678, 2015

13. Mallory GW, Arutyunyan G, Murphy ME, Van Abel KM, Francois E, Wetjen NM, et al: The rise and fall of the craniocervical junction relative to the hard palate: a lifetime story. J Neurosurg Spine 24:521-526, 2016

14. Miyata M, Neo M, Fujibayashi S, Ito H, Takemoto M, Nakamura T: O-C2 angle as a predictor of dyspnea and/ or dysphagia after occipitocervical fusion. Spine (Phila Pa 1976) 34:184-188, 2009

15. Mummaneni PV, Haid RW: Transoral odontoidectomy. Neurosurgery 56:1045-1050, 2005

16. Peng X, Chen L, Wan Y, Zou X: Treatment of primary basilar invagination by cervical traction and posterior 
instrumented reduction together with occipitocervical fusion. Spine (Phila Pa 1976) 36:1528-1531, 2011

17. Qiu F, Yang JC, Ma XY, Xu JJ, Yang QL, Zhou X, et al: Influence of vertebral column distraction on spinal cord volume: an experimental study in a goat model. Arch Orthop Trauma Surg 135:1201-1210, 2015

18. Wei G, Wang Z, Ai F, Yin Q, Wu Z, Ma XY, et al: Treatment of basilar invagination with Klippel-Feil syndrome: atlantoaxial joint distraction and fixation with transoral atlantoaxial reduction plate. Neurosurgery 78:492-498, 2016

19. Yoshizumi T, Murata H, Ikenishi Y, Sato M, Takase H, Tateishi K, et al: Occipitocervical fusion with relief of odontoid invagination: atlantoaxial distraction method using cylindrical titanium cage for basilar invagination-case report. Neurosurg Rev 37:519-525, 2014

\section{Disclosures}

The authors report no conflict of interest concerning the materials or methods used in this study or the findings specified in this paper.

\section{Author Contributions}

Conception and design: Inoue. Acquisition of data: Tateyama. Drafting the article: Inoue. Administrative/technical/material support: Hattori, Ganaha, Kumai. Study supervision: Hirose.

\section{Correspondence}

Tatsushi Inoue: Fujita Health University, Toyoake, Aichi, Japan. spine_expert@mac.com. 